\title{
(2) OPEN ACCESS \\ Unilateral carpal tunnel syndrome: an unusual presentation of nodular fasciitis
}

\author{
Deepak Chouhan, ${ }^{1}$ Mohammed Tahir Ansari (D) , ${ }^{1}$ Devansh Goyal, ${ }^{1}$ \\ Asit Ranjan Mridha
}

${ }^{1}$ Orthopaedics, All India Institute of Medical Sciences, New Delhi, India

${ }^{2}$ Pathology, All India Institute of Medical Sciences, New Delhi, Delhi, India

Correspondence to Dr Mohammed Tahir Ansari; drtahir.ansari@gmail.com

Accepted 22 October 2020

Check for updates

(c) BMJ Publishing Group Limited 2020. Re-use permitted under CC BY-NC. No commercial re-use. See rights and permissions. Published by BMJ.

To cite: Chouhan $D_{\text {, }}$

Ansari MT, Goyal D, et al. BM Case Rep 2020;13:e236142. doi:10.1136/bcr-2020

236142

\section{SUMMARY}

Nodular fasciitis is a benign, self-limiting proliferative disorder of fibroblast of uncertain aetiology, occurs frequently in the forearm. Nodular fasciitis in hand inducing carpal tunnel syndrome is exceptional. There are four cases of non-intraneural nodular fasciitis causing peripheral neuropathy that has been reported previously. We present the case of a 38-year-old man with features of unilateral carpal tunnel syndrome. Decompression of the median nerve performed subsequently along with excision of the lesion in a piecemeal fashion. Histopathological and immunohistochemical findings were consistent with nodular fasciitis. There were complete resolution of symptoms and no sign of recurrence at the end of 1 year after surgery.

\section{BACKGROUND}

Carpal tunnel syndrome (CTS) is the most common peripheral compression neuropathy,rarely caused by the space-occupying lesions (SOLs). There are reports on CTS due to SOLs such as tuberculous synovitis, lipoma, hemangioma, synovial sarcoma, fibroma of the tendon sheath, ganglion cyst, tophaceous gout, volar lunate dislocation, palmaris longus hypertrophy and calcifying mass. ${ }^{1-10}$

Nodular fasciitis is a rare benign, self-limiting proliferation of myofibroblast of unknown aetiology. Although it is usually seen in the subcutaneous region of the upper extremity, the involvement of the hand is very rare. It usually presents as a painless rapidly growing mass. Neurological deficit is rare; suggest either compression of the peripheral nerve or intraneural origin of the tumour. Intraneural nodular fasciitis has been described in eight patients. ${ }^{11-18}$ Only four case reports of non-intraneural nodular fasciitis with the presentation of peripheral neuropathy have been described previously. To our knowledge, this is the first reported case of non-intraneural nodular fasciitis as a space-occupying lesion arising in the palm inducing carpal tunnel syndrome.

\section{CASE PRESENTATION}

A healthy 38-year-old man, presented with problems of occasional pain in his right wrist and tingling sensations in his right thumb, index and middle finger for a duration of 6 weeks. The symptoms had an insidious onset and progressed gradually over 6 weeks when the patient sought medical attention. There was no history of preceding trauma, fever, multiple joint pain or morning stiffness. He had no history of any other medical illness. Physical examination revealed a mild, diffuse fullness over the volar aspect of the wrist. Mild tenderness was present on deep palpation. There was no local rise in temperature. Resisted active finger flexion elicited pain over the wrist. Tinel's sign was positive for the median nerve and Phalen's test was positive. The range of motion at the wrist was comparable to the left wrist. There was no hypoesthesia or motor weakness on the neurological examination.

\section{INVESTIGATIONS}

The laboratory analysis revealed a leucocyte count 4490/cumm (4000-11 000), erythrocyte sedimentation rate of $15 \mathrm{~mm} /$ hour and a $C$ reactive protein $4 \mathrm{mg} / \mathrm{L}$. MRI showed soft-tissue lesion around the flexor pollicis longus tendon, flexor digitorum profundus and superficialis tendons in the region of wrist and palmer bowing of the flexor retinaculum with compression of the median nerve (figure 1). The lesion was isointense on T1-weighted images and homogenous hyperintense on T2-weighted images. A sensory nerve conduction study showed increased distal latency, decreased amplitude and decreased conduction velocity of the median nerve around the wrist.

\section{DIFFERENTIAL DIAGNOSIS}

Based on MRI features, a presumptive diagnosis of hypertrophic synovium as made. The differential diagnoses were broad, based on the histopathological finding of benign spindle cell lesion. Therefore, the possibility of fibroma, proliferative myositis, nodular fasciitis, solitary fibrous tumour, schwannoma, low-grade spindle cell carcinoma and low-grade fibrosarcoma were all considered in this case. These lesions were ruled out by immunohistochemical findings. Expression of smooth muscle actin along with negative staining with S-100 excludes the origin of tumour from neural tissue. The negative expression for cytokeratin, epithelial membrane antigen rules out spindle cell carcinoma. CD34 and Bcl2 negative staining rule out a solitary fibrous tumour.

\section{TREATMENT}

The patient underwent a flexor tenosynovectomy and carpal tunnel release under WALANT (Wide Awake Local Anaesthesia No Tourniquet). Consistent with the MRI findings, intraoperatively, we found abundant hypertrophied tissue in the carpal tunnel around the flexor tendons compressing the median nerve. The lesion was resected in piecemeal and sent for histopathological examination. 


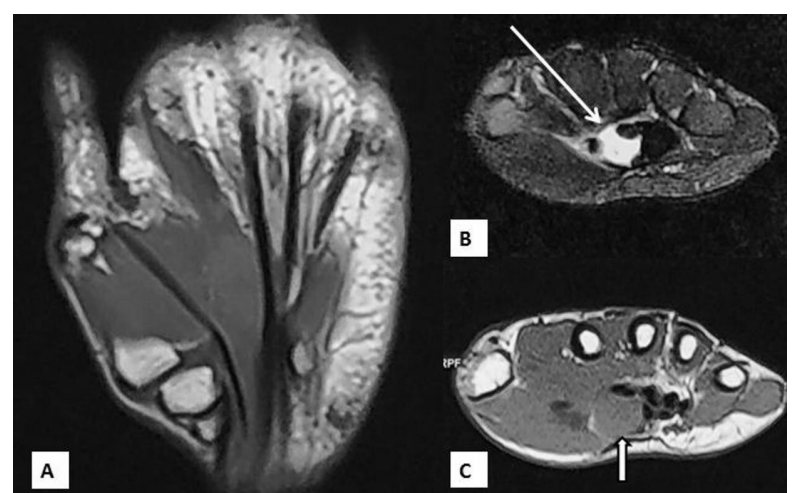

Figure 1 Preoperative magnetic resonance images. (A) T1-weighted coronal section shows an isointense lesion. (B) T2-weighted axial section (arrow). (C) T1-weighted axial section shows a space-occupying lesion (arrow) adjacent to the median nerve.

Histopathology showed spindle cell proliferation with a fascicular pattern of arrangement with an extensive myxoid matrix (figure 2). The cells had plump vesicular nuclei and a moderate amount of eosinophilic cytoplasm. A variable amount of collagen was seen in the background. Few mitotic figures were noted. No necrosis was seen. The spindle cells were immunopositive for smooth muscle actin but negative for S100 protein, desmin, myogenin, CD34, $\beta$-catenin, STAT6, Pan-cytokeratin, epithelial membrane antigen and $\mathrm{Bcl} 2$. MIB1 proliferation index was about 5\% in the height proliferative area (figure 2). Overall features were consistent with nodular fasciitis.

The histopathological features were very characteristic of nodular fascitis and in cases of doubt, FISH for USP6 gene rearrangement to confirm the diagnosis can be done. In this case, it was not performed because of typical histopathological findings.

\section{OUTCOME AND FOLLOW-UP}

Sensory symptoms resolved in 24 hours. At a 2-month follow-up, patient had occasional numbness over the right thumb. At

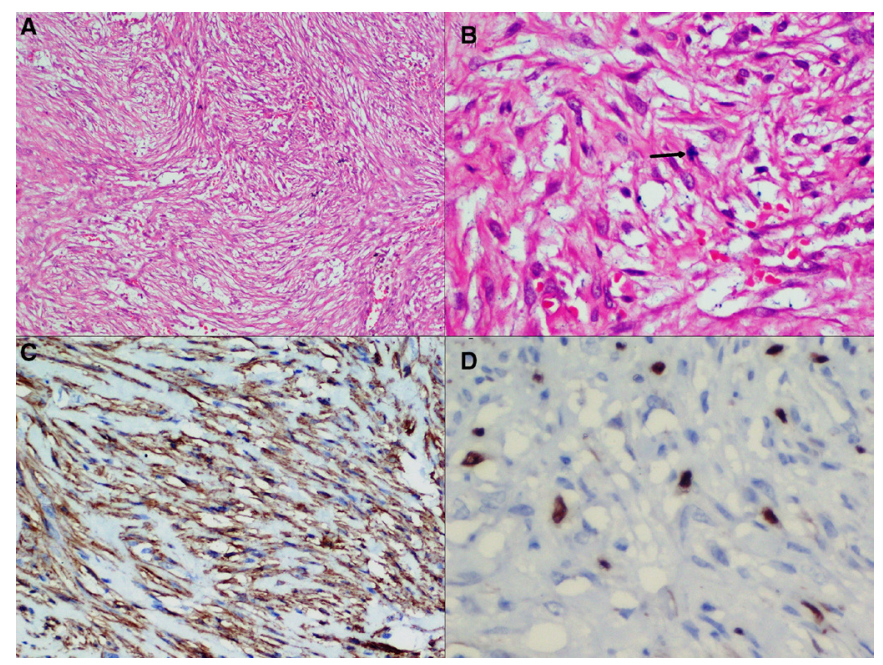

Figure 2 H\&E stained sections show a spindle cell lesion with vague nodular and intersecting fascicular pattern $(A, H \& E \times 100)$. The cells resemble myofibroblasts with vesicular to hyperchromatic nuclei, and eosinophilic cytoplasm. Mitotic figure is present (arrow). Extravasated RBCs and myxoid background are seen ( $B, H \& E \times 400)$. The cells are immunopositive for smooth muscle actin $(C, \times 200)$. MIB1 proliferation index is about $5 \%(D, \times 400)$. 12-month follow-up, there were complete resolution of symptoms with no sign of recurrence.

\section{DISCUSSION}

CTS cases are usually idiopathic and bilateral. A literature review showed that the majority of unilateral carpal tunnel syndrome was caused by SOLs. In a study by Nakamichi et al, out of 20 patients with unilateral carpal tunnel syndrome, SOLs were found in 7 patients and none of the 89 patients with bilateral carpal tunnel syndrome had SOLs. ${ }^{19}$ In a study of 23 patients of carpal tunnel syndrome with space-occupying lesions by Chen et al, only 3 patients were found to have bilateral involvement. ${ }^{20}$ The present case report showed unilateral carpal tunnel syndrome induced by nodular fasciitis.

Nodular fasciitis is a rare benign self-limiting fibrous tumour that usually presents as a painless, rapidly growing subcutaneous mass. It is most commonly diagnosed in young, middle-aged adults in their third to fourth decade. ${ }^{21} 22$ It affects both men and women equally. Forearm (27\%-29\%) is the most common site followed by back or chest wall (15\%-18\%), upper arm $(12 \%)$ and extremely rare in hand $(0 \%-2 \%) .{ }^{21-24}$ It has been reported in almost all other tissues with the notable exception of the visceral organs. The most common presentation is painless growing or stable mass. The presence of tingling, numbness or weakness suggests either intraneural origin or compression of the nerve by non-intraneural nodular fasciitis. Eight cases of intraneural nodular fasciitis (two ulnar nerve, two sciatic nerve, one obturator nerve, two median nerve, one radial nerve) have been reported. ${ }^{11-18}$

Peripheral neuropathy is an unusual symptom in nodular fasciitis. There are only four case reports of non-intraneural nodular fasciitis with presenting features of peripheral neuropathy. One case was the entrapment of radial nerve secondary to a solitary nodular fasciitis mass in the forearm. ${ }^{25}$ Another case was axillary nerve palsy secondary to nodular fasciitis that arose in the quadrilateral space. ${ }^{26}$ Third case was presented as a mass in the palm with peripheral neuropathy affecting the digital nerve of the middle finger. ${ }^{27}$ The fourth case was ulnar nerve compression induced by nodular fasciitis in the cubital tunnel. ${ }^{17}$ To our knowledge, we report the first case of median nerve compression induced by non-intraneural nodular fasciitis in hand.

Nodular fasciitis is classified into three subtypes, myxoid, cellular and fibrous based on histological composition. Myxoid type corresponds to younger lesion while fibrous composition corresponds to older lesions. ${ }^{24}$ There is no specific signal intensity has been described on MRI in nodular fasciitis. ${ }^{28}$ The differences in signal intensity on T2-W images may be attributed to variability in histological composition. ${ }^{29}$ Due to lack of specificity and overlapping features with tenosynovitis, myositis or sarcomas on MRI, a preoperative diagnosis could not be made, mandates histopathologicalanalysis. However, MRI appearance may be correlated with the stage of the disease. In the present study, the hyperintense appearance of the lesion on T2-W images may correspond to the histopathological findings of the myxoid matrix with proliferating fibroblasts. It is important to differentiate nodular fasciitis from other disorders that have a close resemblance and can be the possible differentials for SOLs leading to CTS. These include palmer fibromatosis, ${ }^{30}$ calcific tendinitis, ${ }^{31}$ systemic multifocal fibrosclerosis (IgG4 disease), ${ }^{32}$ lipomatosis, ${ }^{33}{ }^{34}$ linear scleroderma, ${ }^{35} 36$ eosinophilic fasciitis ${ }^{36}$ and checkpoint inhibitor induced fasciitis. The definitive diagnosis is however possible with histopathological examination only. 
Learning points

- All cases of unilateral carpal tunnel syndrome (CTS) should be closely monitored and surgeons should be suspicious about the possibility of soft-tissue tumours.

- Nodular fasciitis should be kept in the differential diagnosis of space-occupying lesions of carpal tunnel.

- Differentiation of nodular fasciitis from other morphologically similiar malignant lesions is crucial to avoid unnecessary aggressive surgical excision.

- A preoperative MRI and intraoperative biopsy should be considered routinely in every unilateral case of CTS.

Contributors DC wrote the manuscript. DG collected the data, followed up the patient. ARM did histopathology of the specimen and provided his inputs for the differential diagnosis. MTA operated the patient, followed up the patient and provided guidance for initial writing. He did proofread the article and wrote the final version of the manuscript.

Funding The authors have not declared a specific grant for this research from any funding agency in the public, commercial or not-for-profit sectors.

Competing interests None declared.

Patient consent for publication Obtained.

Provenance and peer review Not commissioned; externally peer reviewed.

Open access This is an open access article distributed in accordance with the Creative Commons Attribution Non Commercial (CC BY-NC 4.0) license, which permits others to distribute, remix, adapt, build upon this work non-commercially, and license their derivative works on different terms, provided the original work is properly cited and the use is non-commercial. See: http://creativecommons.org/ licenses/by-nc/4.0/.

\section{ORCID iD}

Mohammed Tahir Ansari http://orcid.org/0000-0002-4609-6891

\section{REFERENCES}

1 Kang HJ, Park SY, Shin SJ, et al. Tuberculous tenosynovitis presenting as carpal tunnel syndrome. J Korean Soc Surg Hand 2000;5:137-41.

2 Kremchek TE, Kremchek EJ. Carpal tunnel syndrome caused by flexor tendon sheath lipoma. Orthop Rev 1988;17:1083-5.

3 Coessens B, De Mey A, Lacotte B, et al. Carpal tunnel syndrome due to an haemangioma of the median nerve in a 12-year-old child. Ann Chir Main Memb Super 1991;10:255-7.

4 Weiss AP, Steichen JB. Synovial sarcoma causing carpal tunnel syndrome. J Hand Surg Am 1992;17:1024-5.

5 Evangelisti S, Reale VF. Fibroma of tendon sheath as a cause of carpal tunnel syndrome. J Hand Surg Am 1992;17:1026-7.

6 Kerrigan JJ, Bertoni JM, Jaeger SH. Ganglion cysts and carpal tunnel syndrome. J Hand Surg Am 1988; 13:763-5

7 Pai CH, Tseng CH. Acute carpal tunnel syndrome caused by tophaceous gout. J Hand Surg Am 1993;18:667-9.
8 Chen WS. Median-Nerve neuropathy associated with chronic anterior dislocation of the lunate. J Bone Joint Surg Am 1995;77:1853-7.

9 Backhouse KM, Churchill-Davidson D. Anomalous palmaris longus muscle producing carpal tunnel-like compression. Hand 1975:7:22-4.

10 Edwards AJ, Sill BJ, Macfarlane I. Carpal tunnel syndrome due to dystrophic calcification. ANZ J Surg 1984:54:491-2.

11 Mahon JH, Folpe AW, Ferlic RJ. Intraneural nodular fasciitis: case report and literature review. J Hand Surg Am 2004;29:148-53.

12 Ikeda K, Hagiwara N, Funaki K, et al. Nodular fasciitis of the ulnar nerve at the palm. Scand J Plast Reconstr Surg Hand Surg 2005;39:249-51.

13 Parrett BM, Orgill DP, Marsee DK, et al. Novel presentation of intraneural nodular fasciitis of the sciatic nerve. J Peripher Nerv Syst 2007;12:61-3.

14 Fallah A, Grochmal J, Lu J-Q, et al. Nodular fasciitis presenting in the obturator nerve and gracilis muscle. Can J Neurol Sci 2008;35:111-4

15 Kakutani K, Doita M, Nishida K, et al. Intractable sciatica due to intraneural nodular fasciitis detected by positron emission tomography. Spine 2010;35:E1137-40.

16 Sundar SJ, Healy AT, Shook SJ, et al. Intraneural nodular fasciitis of the radial nerve with rapidly progressive motor symptoms. Surg Neurol Int 2016;7:28.

$17 \mathrm{Kim} \mathrm{H}$, Baik MW, Kim J, et al. Ulnar nerve compression in the cubital tunnel by a nodular fasciitis. Clin Neurol Neurosurg 2011;113:803-5.

18 Yano K, Kazuki K, Yoneda M, et al. Intraneural nodular fasciitis of the median nerve: case report and literature review. J Hand Surg Am 2011:36:1347-51.

19 Nakamichi K, Tachibana S. Unilateral carpal tunnel syndrome and space-occupying lesions. J Hand Surg Br 1993:18:748-9.

20 Chen C-H, Wu T, Sun J-S, et al. Unusual causes of carpal tunnel syndrome: space occupying lesions. J Hand Surg Eur Vol 2012:37:14-19.

21 Stout AP. Pseudosarcomatous fascitis in children. Cancer 1961;14:1216-22.

22 Brimhall CL, Segura AD, McTique MK, et al. Nodular fasciitis on the palm of a child. Arch Dermatol 1989;125:1441-2.

23 Bernstein KE, Lattes R. Nodular (pseudosarcomatous) fasciitis, a nonrecurrent lesion: clinicopathologic study of 134 cases. Cancer 1982;49:1668-78.

24 Shimizu S, Hashimoto H, Enjoji M. Nodular fasciitis: an analysis of 250 patients. Pathology 1984;16:161-6.

25 Ilan DI, Medvecky M, Raskin KB, et al. Radial nerve entrapment secondary to a solitary nodular fasciitis mass in the forearm. Am J Orthop 2006:35:85-7.

26 Nishida Y, Koh S, Fukuyama Y, et al. Nodular fasciitis causing axillary nerve palsy: a case report. J Shoulder Elbow Surg 2010;19:e1-4.

27 Emori M, Shimizu J, Murahashi Y, et al. Nodular fasciitis involving the palm. Ann R Coll Surg Eng/ 2018:100:e128-31.

28 Leung LYJ, Shu SJ, Chan ACL, et al. Nodular fasciitis: MRI appearance and literature review. Skeletal Radiol 2002:31:9-13.

29 Wang XL, De Schepper AMA, Vanhoenacker F, et al. Nodular fasciitis: correlation of MRI findings and histopathology. Skeletal Radiol 2002;31:155-61.

30 Ioana T, Lascar I, Valcu M, et al. Dupuytren's disease digital radius IV right hand and carpal tunnel syndrome on ipsilateral hand. ARS Medica Tomitana 2015;21.

31 McRae B, Nusem L. A rare case of acute carpal tunnel syndrome secondary to calcific tendinitis: a case report. Open Orthop J 2019;13:198-201.

32 Sica A, Casale B, Spada A, et al. Differential diagnosis: retroperitoneal fibrosis and oncological diseases. Open Med 2018;15:22-6.

33 Sbai MA, Benzarti S, Msek H, et al. Carpal tunnel syndrome caused by lipoma: a case report. Pan Afr Med J 2015:22:51

34 Aydin A. Carpal tunnel syndrome caused by intraneural lipoma of the median nerve and arteriovenous malformation. J Cutan Aesthet Surg 2018;11:29-32.

35 Winkelmann RK, Connolly SM, Doyle JA. Carpal tunnel syndrome in cutaneous connective tissue disease: generalized morphea, lichen sclerosus, fasciitis, discoid lupus erythematosus, and lupus panniculitis. J Am Acad Dermatol 1982;7:94-9.

36 Morgan ND, Hummers LK. Scleroderma mimickers. Curr Treatm Opt Rheumatol 2016;2:69-84

Copyright 2020 BMJ Publishing Group. All rights reserved. For permission to reuse any of this content visit

https://www.bmj.com/company/products-services/rights-and-licensing/permissions/

BMJ Case Report Fellows may re-use this article for personal use and teaching without any further permission.

Become a Fellow of BMJ Case Reports today and you can:

- Submit as many cases as you like

- Enjoy fast sympathetic peer review and rapid publication of accepted articles

- Access all the published articles

- Re-use any of the published material for personal use and teaching without further permission

Customer Service

If you have any further queries about your subscription, please contact our customer services team on +44 (0) 2071111105 or via email at support@bmj.com.

Visit casereports.bmj.com for more articles like this and to become a Fellow 